\title{
Yorkshire practice highly commended for apprentice scheme
}

ental practice Michael and Margaret
Naylor and Associates have been highly commended at the national final of the National Apprenticeship Awards 2016.

The Awards, now in their thirteenth year, are run by the National Apprenticeship Service and recognise excellence in two areas: businesses that grow their own talent with apprentices and apprentices who have made a significant contribution to their workplaces.

With a small workforce of 37 employees, Michael and Margaret Naylor and Associates dental practice, based in South Yorkshire, have been committed to apprenticeships for almost 20 years currently employing nine apprentices in different roles across the company.

The practice, who won Yorkshire and the Humber Medium Employer of the Year at the National Apprenticeship Awards, began by offering an advanced apprenticeship in dental nursing. More recently, the ongoing success of apprenticeships at the practice has encouraged the organisation to expand their programme to include level 2 apprenticeships in business administration and customer service.

The practice is committed to investing in apprenticeships. Margaret Naylor, principal dentist, said: 'We find taking on apprentices who are prepared to work hard, alongside studying for a qualification, helps create a motivated and enthusiastic workforce.' This is reflected in an increase in staff retention and loyalty - with over $90 \%$ of the practice's full-time staff having progressed into their roles following an apprenticeship.

The advantages brought by apprenticeships to the practice, however, have gone beyond business benefits. They've also had a profound impact upon the local community. Margaret explained:

'Working in a poor socioeconomic area, where the majority of opportunities are in the manual or service industries, the apprenticeships our practice offers can provide a tremendous life opportunity for someone, and the first step on the career ladder'

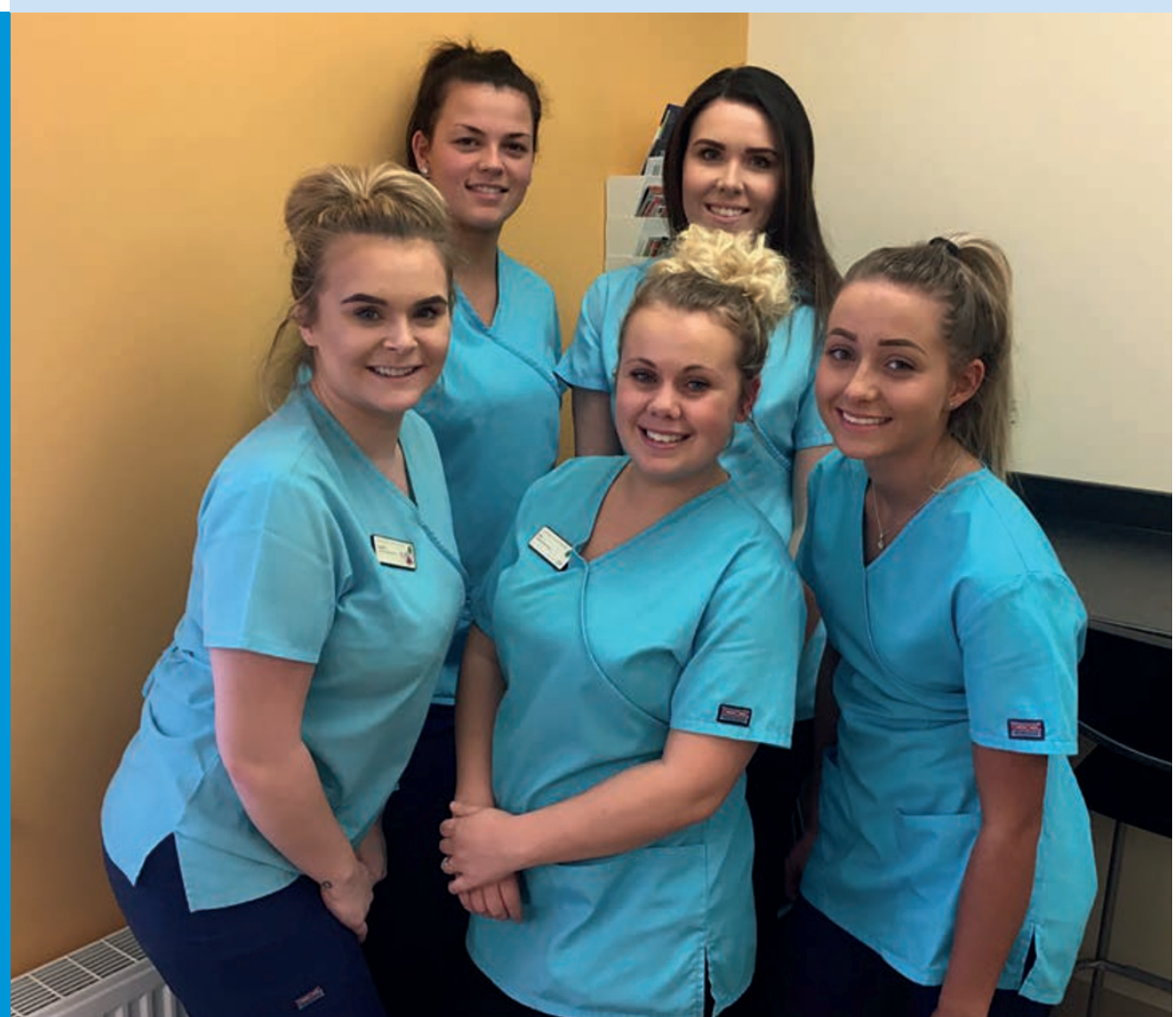

Apprentices at Michael and Margaret Naylor and Associates; from left to right Sophie Keady, Ellie Baines, Bethany Gwalter, Alice Kirk and Chloe Kelly

\section{GDC calls for better collaboration in new regalatory plans}

On 26 January the General Dental Council (GDC) announced plans for how its approach to regulating dental professionals will be reformed to put public safety firmly at its heart.

In a document entitled Shifting the balance: a better, fairer system of dental regulation the GDC said that it will:

- Support and empower the profession through a range of education, learning and development activities

- Support patients to feel confident their concerns are appropriately raised and resolved by the right body at the right time

- Continue its commitment to work better with partners to improve the regulation of dentistry in the UK

- Make it clear how and when it will use its formal FtP enforcement powers to manage serious risk to patients.

Ian Brack, Chief Executive of the GDC, said: 'This is our most significant proposal in a generation and I encourage anyone involved with dental services to engage with our plans.

'We have made it clear from the outset that we cannot do this alone - the proposals require fundamentally better collaboration with others than we have achieved in the past.

'I am confident that our proposals can make the system better for patients and fairer for dental professionals and strengthen public confidence in dental services.'

To read the full document and to comment on the GDC's proposals, visit http://www.gdc-uk.org/ Newsandpublications/consultations/Pages/ Reforming-dental-professional-regulation. aspx. The discussion document closes on 26 April 2017.

An interview with DCP Kirstie Moons, a member of the GDC Council, is featured this March in BDJ Team 